\title{
BMJ Open What factors are associated with pre- pregnancy nutritional status? Baseline analysis of the KITE cohort: a prospective study in northern Ethiopia
}

\author{
Kebede Haile Misgina (D , , ${ }^{1,2} \mathrm{H}$ Marike Boezen, ${ }^{1}$ Eline M van der Beek, ${ }^{3}$ \\ Afework Mulugeta, ${ }^{4}$ Henk Groen (D) ${ }^{1}$
}

To cite: Misgina KH, Boezen HM, van der Beek EM, et al. What factors are associated with pre-pregnancy nutritional status? Baseline analysis of the KITE cohort: a prospective study in northern Ethiopia. BMJ Open 2021;11:e043484. doi:10.1136/ bmjopen-2020-043484

- Prepublication history for this paper is available online. To view these files, please visit the journal online (http://dx.doi. org/10.1136/bmjopen-2020043484).

Received 19 August 2020 Accepted 08 June 2021

Check for updates

(C) Author(s) (or their employer(s)) 2021. Re-use permitted under CC BY-NC. No commercial re-use. See rights and permissions. Published by BMJ.

${ }^{1}$ Department of Epidemiology, University of Groningen, Groningen, The Netherlands ${ }^{2}$ Department of Public Health, Aksum University, Axum, Ethiopia

${ }^{3}$ Department of Paediatrics, University of Groningen, Groningen, The Netherlands

${ }^{4}$ Department of Nutrition, University of Mekelle, Mekelle, Ethiopia

Correspondence to Kebede Haile Misgina; k.h.misgina@umcg.nl

\section{ABSTRACT}

Objective To assess a broad range of factors associated with pre-pregnancy nutritional status, a key step towards improving maternal and child health outcomes, in Ethiopia. Design A baseline data analysis of a population-based prospective study.

Setting Kilite-Awlaelo Health and Demographic Surveillance Site, eastern zone of Tigray regional state, northern Ethiopia.

Participants We used weight measurements of all 17500 women of reproductive age living in the surveillance site between August 2017 and October 2017 as a baseline. Subsequently, 991 women who became pregnant were included consecutively at an average of 14.8 weeks (SD: 1.9 weeks) of gestation between February 2018 and September 2018. Eligible women were married, aged 18 years or older, with a pre-pregnancy weight measurement performed, and a gestational age $\leq 20$ weeks at inclusion.

Outcome measures The outcome measure was prepregnancy nutritional status assessed by body mass index (BMI) and mid-upper arm circumference (MUAC). Undernutrition was defined as BMl of $<18.5 \mathrm{~kg} / \mathrm{m}^{2}$ and $/$ or MUAC of $<21.0 \mathrm{~cm}$. BMl was calculated using weight measured before pregnancy, and MUAC was measured at inclusion. Linear and spline regressions were used to identify factors associated with prepregnancy nutritional status as a continuous and Poisson regression with pre-pregnancy undernutrition as a dichotomous variable.

Results The mean pre-pregnancy BMl and MUAC were $19.7 \mathrm{~kg} / \mathrm{m}^{2}\left(\mathrm{SD}: 2.0 \mathrm{~kg} / \mathrm{m}^{2}\right.$ ) and $22.6 \mathrm{~cm}$ (SD: $1.9 \mathrm{~cm}$ ), respectively. Overall, the prevalence of prepregnancy undernutrition was $36.2 \%$ based on BMI and/ or MUAC. Lower age, not being from a model household, lower values of women empowerment score, food insecurity, lower dietary diversity, regular fasting and low agrobiodiversity showed significant associations with lower BMl and/or MUAC.

Conclusion The prevalence of pre-pregnancy undernutrition in our study population was very high. The pre-pregnancy nutritional status could be improved by advancing community awareness on dietary practice and gender equality, empowering females, raising agricultural productivity and strengthening health extension. Such changes require the coordinated efforts of concerned
Strengths and limitations of this study

- One of the strengths is measuring weight in a distinct period before starting the inclusion of women.

- Including a relatively large sample of women and collecting information on many possible confounders can be considered strengths.

- As for limitations, mid-upper arm circumference (MUAC) was measured at inclusion, unlike body mass index, but as MUAC is insensitive to change over time, it can safely represent the pre-pregnancy status.

- Finally, seasonal variation was not considered in dietary diversity measurements.

governmental bodies and religious leaders in the Ethiopian setting.

\section{INTRODUCTION}

Undernutrition continues to be a public health problem in developing countries. ${ }^{1}$ For women, undernutrition not only directly affects their current health, but it can also lead to additional health problems when they get pregnant. Maternal undernutrition is related to pregnancy complications like anaemia and hypertension, and also to adverse birth outcomes such as low birth weight and preterm birth. ${ }^{2-7}$ These adverse outcomes, in turn, are related to short-term and long-term adverse health outcomes of the mothers and their offspring. ${ }^{1-11}$ Clearly, pre-pregnancy undernutrition, defined as low body mass index (BMI) of $<18.5 \mathrm{~kg} / \mathrm{m}^{2}$ and/ or mid-upper arm circumference (MUAC) of $<21 \mathrm{~cm}$, contributes to the vicious cycle of transgenerational malnutrition and its subsequent effects. ${ }^{111}$

Pre-pregnancy undernutrition is widespread in developing countries. ${ }^{12-15}$ According to a recent review, nearly $32 \%$ of pregnant women were undernourished 
(MUAC: $<21 \mathrm{~cm}$ ) in Africa. ${ }^{16}$ Since MUAC is relatively insensitive to short-term change, this could also reflect pre-pregnancy nutritional status. ${ }^{1718}$ In Ethiopia, the prevalence of undernutrition among non-pregnant women of reproductive age was $22 \%$ in $2016 .{ }^{14}$ The problem may be even more profound in Tigray, a region in northern Ethiopia repeatedly hit by drought and war. ${ }^{14}{ }^{19}$ According to a study among non-pregnant women of reproductive age in the Kunama population, a minority group in Tigray, the prevalence of undernutrition was about $48 \% .{ }^{19}$ These studies support the significant importance for public health of pre-pregnancy undernutrition and indicate substantial regional variation in developing countries like Ethiopia.

Factors that may influence pre-pregnancy nutritional status include socioeconomic, ${ }^{13}$ 19-22 reproductive and obstetric conditions, food and dietary habits, ${ }^{19} 2324$ and psychosocial characteristics. Few studies have investigated the factors associated with pre-pregnancy nutritional status in low-income countries like Ethiopia in detail. ${ }^{1922}$ The previous studies also did not control potential confounders like implementing a health extension package, fasting, agrobiodiversity and psychosocial characteristics. ${ }^{25-27}$ Likewise, the role of women's empowerment, the process by which women who have been denied the ability to make strategic life choices acquire such an ability, expressed by their economic, socio-familial and legal empowerment, did not get attention yet. ${ }^{28}$

Furthermore, other studies focused on specific population subgroups only, such as urban residents who may not represent the large majority of the population living in rural conditions ${ }^{22}$ or population groups with different socioeconomic and cultural characteristics. ${ }^{19}$ Knowledge about factors associated with pre-pregnancy nutritional status among women of reproductive age, the target population for interventions to achieve improvement, is, therefore, limited in countries like Ethiopia. The present study aimed to assess a wide range of factors associated with pre-pregnancy nutritional status, a key step towards identifying possible targets for intervention and support to improve maternal and child health outcomes in rural and urban areas of northern Ethiopia.

\section{METHODS}

\section{Study design, setting and population}

The present study, a baseline analysis of an ongoing population-based prospective study, the KIlite-Awlaelo Tigray Ethiopia (KITE) cohort, was conducted in KiliteAwlaelo Health and Demographic Surveillance Site (KAHDSS) between February 2018 and September 2018. The KITE cohort was designed to assess maternal nutrition prior to and during pregnancy, adverse birth outcomes and child growth. KA-HDSS is located in the eastern zone of the Tigray region of northern Ethiopia. The surveillance site consists of 10 rural and 3 urban kebeles (the smallest administrative units) spread across three districts: KiliteAwlaelo, Wukro and Atsbi-Wonberta. Climatic conditions, rural-urban composition, altitude and disease burden were considered in selecting the kebeles to represent the population of the Tigray region.

The total population of the KA-HDSS is 113760 . With $24 \%$ of the population being women of reproductive age, about 4550 pregnancies are expected per year within the KA-HDSS. Most of the population lives in rural settings, and agriculture is the primary source of income. Ethiopia has a three-tier healthcare system with health posts at the forefront of primary care. Each kebele has one health post staffed by two to three health extension workers (HEWs). Health posts provide promotional and preventive services under the umbrella of the "health extension package' mainly at a household level. The health extension package consists of 16 components, including maternal health, family planning, nutrition and sanitation. ${ }^{25}$

Pregnant women living in the study area, whose expected date of delivery lay before the end of January 2019, were the study population. Married women, aged 18 years or older, whose pre-pregnancy weight was measured and who completed $\leq 20$ weeks of gestation, were eligible to be included in the study. The sample size was calculated to address the objectives of the KITE cohort. The critical assumption included a 5\% $\alpha$ level (two-sided) and $80 \%$ power to find a difference of $24.6 \%$ low birth weight among women with MUAC of $\geq 23.0 \mathrm{~cm}$ versus $32.6 \%$ among women with MUAC of $<23.0 \mathrm{~cm}{ }^{7}$ Taking an estimated $10 \%$ dropout rate into account, the total sample size was calculated at 1100 . With this sample size, effect sizes $>0.2$ SD for continuous outcomes could also be detected.

Different methods were applied to identify pregnant women, including a community-based survey by HEWs through the 'Women Development Army', a network of health information workers reaching individual households around the health posts. The records of the nearby antenatal clinics and the KA-HDSS database were also used. In addition, we identified pregnant women through two ongoing projects in Ethiopia. The first project concerns a Productive Safety Net Programme that is being implemented, aiming to improve food security through the participation of households in community asset building projects and earn a wage either in cash or in-kind. Also, households are expected to participate in soil and water conservation activities at least 20 days per year for free. In both cases, pregnant women are exempted on reporting their pregnancy status to the HEWs, allowing us to identify them for participation.

Furthermore, a campaign offering trachoma treatment was taking place during the data collection period. As the treatment is contraindicated in the first trimester of pregnancy, women had to report their pregnancy status to HEWs. The opportunity was, therefore, used to identify pregnant women. All eligible pregnant women identified during the study period through any of the methods mentioned above were visited at their homes, invited for the study and included consecutively. 


\section{Measurements}

The pre-pregnancy weight of women of reproductive age $(\mathrm{N}=17500)$ living in the study area was measured between August 2017 and October 2017 using a Seca scale to the nearest $100 \mathrm{~g}$ at a community level in collaboration with the district health and KA-DHSS offices. Subsequently, the identification and inclusion of pregnant women took place. At inclusion, data were collected by intervieweradministered questionnaire, anthropometric measurements as per standard techniques ${ }^{29}$ and extracting data available in the KA-DHSS database. The questionnaire was adapted from the literature ${ }^{7430-34}$ and pretested on 55 pregnant women selected based on their accessibility in Tahtay-Maychew, central zone, Tigray region. Data including the pre-pregnancy weight were collected by qualified HEWs, and the data collection included the following.

\section{Socioeconomic variables}

Age in complete years, residence (urban or rural), religion (Orthodox, Catholic, Muslim or others), educational status (no formal education, primary education or secondary education and above), occupation (farmer, housewife, employed or others), husband educational status (no formal education, primary education or secondary education and above), husband occupation (farmer, employed, daily labourer or others), family size, that is, the number of people living in the same household, and wealth index were extracted from the KA-DHSS database. The surveillance site updates the database every 6 months except for wealth index. The last update for wealth index was done in 2015 in most of the kebeles and in 2017 in two kebeles that were included into the surveillance site recently. Therefore, adjustment was made at inclusion when there was a change since the last update.

Wealth index was assessed by asking about housing characteristics, access to improved drinking water and sanitation facilities, and ownership of household assets, land and livestock. First, the dichotomised socioeconomic proxy indicator variables were standardised using principal component analysis, and factor coefficient scores were created. Then, the indicator values were multiplied by the factor scores and summed to produce a standardised wealth index value. Finally, using the factor scores with the largest proportion of the variance, the wealth index was categorised into quintiles designating the lowest to the highest economic status. ${ }^{35}$ Access to improved drinking water sources refers to access to piped water on-premises, public taps or standpipes, tube wells or boreholes, protected dug wells, protected springs and/ or rainwater collection. Similarly, access to an improved sanitation facility is defined as access to an unshared toilet facility, pit latrine with a slab, ventilated improved pit latrine or flush toilet. ${ }^{36}$

Furthermore, time to fetch water was collected at inclusion by asking, "What is the time needed to fetch improved drinking water from the nearest source in minutes?'. Then, it was dichotomised at a cut-off point of
30 with the time needed not exceeding 30 min showing better service. ${ }^{36}$ Likewise, access to health service was measured at inclusion by asking the time needed to go to the nearest health facility and back home, with $\leq 1$ hour indicating better access. Also, implementation of the health extension package was assessed by checking if the women's households were certified as model households or not at inclusion. A model household was defined as a household that received short-term training on the health extension package as described above and subsequently implemented the package. ${ }^{25-27}$ Moreover, history of prepregnancy illnesses were recorded at inclusion.

To assess work burden, women were asked to rate their work as easy, moderate or difficult at inclusion. Moreover, physical activity data were obtained at inclusion using the International Physical Activity Questionnaire short form, ${ }^{34} 37$ by asking women about the kinds of physical activities_-vigorous, moderate and walking-they did in the preceding week. Also, they were probed for how many days and how long per day they did each activity. Then, the data were summarised as low, moderate or high physical activity using the algorithm described in the scoring protocol. $^{37}$

\section{Reproductive and obstetric conditions}

Gestational age at inclusion was estimated from selfreported last menstrual period, fundal palpation and/or ultrasound. The latter two were extracted from antenatal records. Gravidity, that is, the number of previous pregnancies, parity, history of abortion, and stillbirth were extracted from the KA-DHSS database. Also, age at first marriage, age at first birth, previous inter-birth spacing in months, history of preterm birth, delivery by Caesarean section and severe perinatal haemorrhage were collected by interview at inclusion. Based on this information, a history of adverse pregnancy outcomes was defined as having experienced one or more of the following: abortion, stillbirth, preterm birth, severe perinatal haemorrhage or delivery by Caesarean section. Furthermore, self-reported information on intimate partner violence was obtained using the four-item Hurt, Insult, Threaten and Scream Questionnaire at inclusion. Each question was rated from 1 to 5 , and a total score of $>10$ was used as a cut-off for the presence of violence. ${ }^{38}$

To assess women empowerment, participants were asked nine questions addressing five domains at inclusion: (1) earning and control over income (relative income to husband, control over men's income and control over women's income); (2) decision-making on household purchases; (3) mobility and healthcare autonomy (decision-making on family visits and women's health); (4) attitude towards domestic violence and (5) ownership of assets (farmland and house). ${ }^{1423} 39$ By coding each positive response as 1 and adding the responses, a women empowerment score ranging from 0 to 9 was obtained. Also, assigning each domain an equal weight (1) to be shared by the indicators within the respective 
domains, women who scored $\geq 80 \%$ or at least 4 out of 5 were considered as empowered. ${ }^{40}$

\section{Food and diet}

Self-reported agrobiodiversity, harvest volume, food insecurity, dietary diversity, number of meals per day, fasting and frequencies of vegetables, fruits, animals-source food, alcohol and coffee intake were obtained at inclusion. Fasting is abstaining from animal-source foods such as meat, dairy products and egg for religious reasons. Christians fast almost every Wednesday and Friday weekly throughout the year, in addition to the long fast times. The longer fasting periods include the 40-day Christmas fast, the 55-day Lenten fast, the 14-day Apostles fast and the 14-day Dormition fast. Data on fasting wre collected by asking women if they fast weekly and adhere to the long fast times. Finally, women were categorised as fasting if they fasted both the weekly and the long fasting times.

To assess agrobiodiversity, women were queried using a list of crops and livestock products and were asked to indicate whether their households produced any of these in the preceding year by 'yes' or 'no' options. Products from the list were grouped into eight categories: cereals, roots and tubers; pulses; oilseeds; fruits; vegetables; dairy; egg; and meat and poultry. A total agrobiodiversity score from 0 to 8 was calculated based on each category's answers. ${ }^{41}$ Also, the amount of produces of each crop in quintals was asked, and total harvest volume was calculated by adding all.

Dietary diversity was assessed by asking women about consuming a list of foods over a 24-hour period with 'yes' or 'no' as the answer options. ${ }^{33}$ The list was organised into 10 groups: grains, white roots and tubers; pulses; nuts and seeds; dairy; meat, fish and poultry; egg; dark green leafy vegetables; other vitamin A-rich fruit and vegetables; other fruit; and other vegetables. Consumption of foods from 5 or more groups was defined as adequate dietary diversity. ${ }^{33}$

Household Food Insecurity Access Scale was used to collect data concerning food security status. ${ }^{32}$ First, women were asked nine occurrence questions eliciting a 'yes' or 'no' response. Next, each positive response was followed by a frequency-of-occurrence question asking how often the reported food insecurity condition happened in the previous month. Response options were (1) rarely, (2) sometimes or (3) often. The sum of the frequency-ofoccurrence questions across all nine questions yielded a food insecurity score ranging from 0 to 27 . A household was classified as food secure if the response to all occurrence questions was 'no' or if the only 'yes' response concerned the question, 'did you worry that your household would not have enough food' and the frequency of occurrence was 'rarely'. All other households were classified as food insecure. ${ }^{32}$

\section{Psychosocial characteristics}

Partner support was measured by the 5-item Turner Support Scale at inclusion, with each item scored from 0 to 3. A sum score of $<10$ was defined as low. ${ }^{42}$ Also, social support from other social sources was assessed using the Oslo-3 Social Support Scale at inclusion, with total scores ranging from 3 to 14 and $\leq 8$ being considered low. ${ }^{43}$ Totalling the two measures of support, a total social support score was created, and low total social support was defined as low support from partner and other social sources.

Moreover, anxiety, depression and stress were collected at inclusion. The 10-item Edinburgh Postnatal Depression Scale and the 7-item anxiety subscale of the Hospital Anxiety and Depression Scale with each item rated from 0 to 3 were used to measure depression and anxiety. Cutoff points of $\geq 13$ and $\geq 8$ were applied to indicate high symptoms of depression and anxiety, respectively. ${ }^{44}$ For stress, the Perceived Stress Scale was used, with a score for each of the 4 items ranging from 0 to 4 and a cut-off of $\geq 8$ showing high symptoms of stress. ${ }^{46}$ Summing depression, anxiety and stress scores, a total distress score was obtained. Also, the presence of high symptoms in one, two, or three domains of distress, that is, anxiety, depression or stress, was considered to indicate the level of distress.

\section{Anthropometrics}

Height and MUAC to the nearest $0.1 \mathrm{~cm}$ were measured at inclusion using a height-measuring board and MUACmeasuring tape. Also, weight was measured as described earlier. All were measured twice and averaged. Based on pre-pregnancy BMI in $\mathrm{kg} / \mathrm{m}^{2}$ calculated from prepregnancy weight and height at inclusion, women were classified as undernourished (BMI: $<18.5 \mathrm{~kg} / \mathrm{m}^{2}$ ), normal weight (BMI: 18.5-24.9 $\mathrm{kg} / \mathrm{m}^{2}$ ) or overweight (BMI: $\left.\geq 25.0 \mathrm{~kg} / \mathrm{m}^{2}\right)$. Likewise, MUAC $<21.0 \mathrm{~cm}$ was used to define undernutrition. ${ }^{47}$

\section{Data quality control}

Data collection was supervised by health extension supervisors $(\mathrm{BSc})$. Data collectors and supervisors were trained on the protocol for 1 day. Besides regular supervision, $10 \%$ of the completed questionnaires were selected at random to be checked by asking the women again. Also, some of the data were cross-checked with antenatal records.

\section{Statistical analysis}

Data were entered into EpiData V.3.3, verified by re-entering a random selection of $20 \%$ of the completed questionnaires, and analysed with STATA (V.11, Stata Corporation, College Station, Texas, USA). Proportion, mean with SD or median with IQR were used to summarise the characteristics of the participants.

Non-linear associations between pre-pregnancy BMI and MUAC as continuous dependent variables, and the independent variables were investigated, and linear spline regression was applied if indicated (Stata adjust_rcspline package). Non-linearity was initially tested with one-way analysis of variance (ANOVA) comparing mean BMI and mean MUAC by categories of each independent variable. 


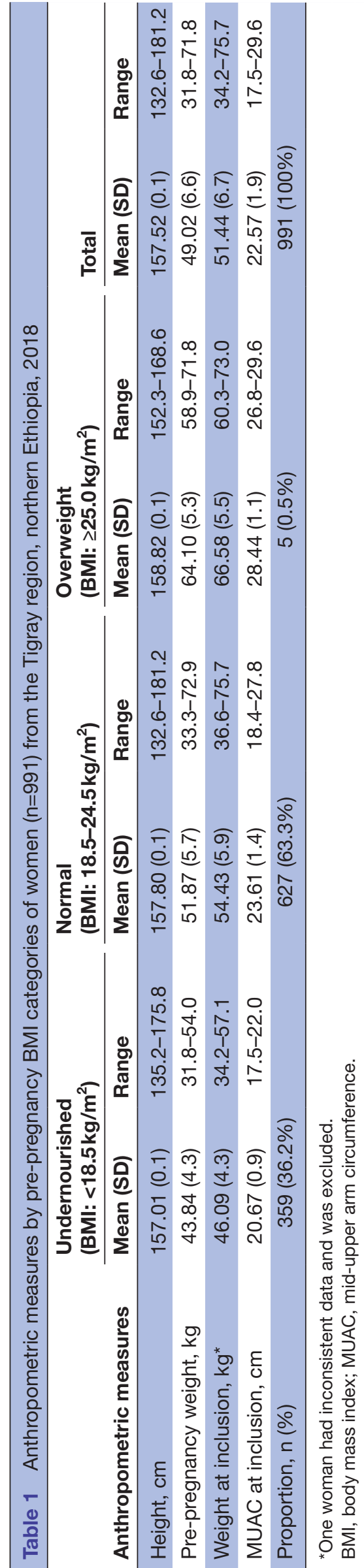

If this test suggested non-linearity as apparent by statistically significant deviation from linearity $(p<0.05)$, two new continuous variables were created by partitioning each independent variable at the knot value $(\mathrm{K})$ into two using linear spline regression. The coefficient for the first variable represented the effect of the variable below the knot value. The coefficient for the second variable reflected the effect at values greater than or equal to the knot value. ${ }^{48}$ The knot value for each variable was roughly estimated by viewing the linear spline regression curves. Subsequently, the knot value resulting in the best fitting linear spline model, that is, a model with the lowest mean squared sum of errors, was determined by testing different values. Then, after regressing the two new variables and their respective intercepts against the corresponding dependent variable (reg BMI int ${ }_{1} \mathrm{X}<\mathrm{K}$ int $_{2} \mathrm{X} \geq \mathrm{K}$, robust), we tested if the slopes of the two variables were different (test $\mathrm{X}<\mathrm{K}=\mathrm{X} \geq \mathrm{K}$ ). If the test showed that the slopes were significantly different $(p<0.05)$, we concluded that the association was non-linear. Finally, after comparing linear spline, quadratic and cubic models, the model that had the best fit, as apparent by the lowest root mean squared sum of errors, was considered in the final analysis. In case linear spline model had the best fit, the two new variables with their intercepts were included in the analysis.

Following the linearity test, linear regression with robust standard errors was used to identify factors associated with pre-pregnancy BMI and MUAC. In the final adjusted linear regression models, relevant variables as per the literature with a statistically significant association $(\mathrm{p}<0.05$, two-sided) in the unadjusted analysis were included. Beta-coefficients with their corresponding $95 \%$ CIs were computed. Residence, occupation, parity and harvest volume were highly correlated with other variables and had a lower correlation with BMI and/or MUAC than their correlates. Thus, they were not included in the final models. As for model diagnostic tests, multicollinearity was checked using the variance inflation factor, and the normality of residuals was checked with histograms, normal probability plots and quantile-quantile plots. Also, specification error and omitted variable bias were tested using the linktest and ovtest commands.

Additionally, Poisson regression with robust variance was used to identify factors associated with pre-pregnancy undernutrition, defined as BMI of $<18.5 \mathrm{~kg} / \mathrm{m}^{2}$ and MUAC of $<21.0 \mathrm{~cm}$ as measured by MUAC. Independent variables significantly associated with pre-pregnancy undernutrition in the unadjusted analysis examined by the $\chi^{2}$ test were included in the final model. Incidence rate ratios with $95 \%$ CI were computed. ${ }^{49}$ All continuous variables were modelled as categorical variables to enhance data convergence and interpretation. Model selection was made based on Akaike and Bayesian Information Criteria.

\section{Patient and public involvement}

There was no patient or public involvement. 


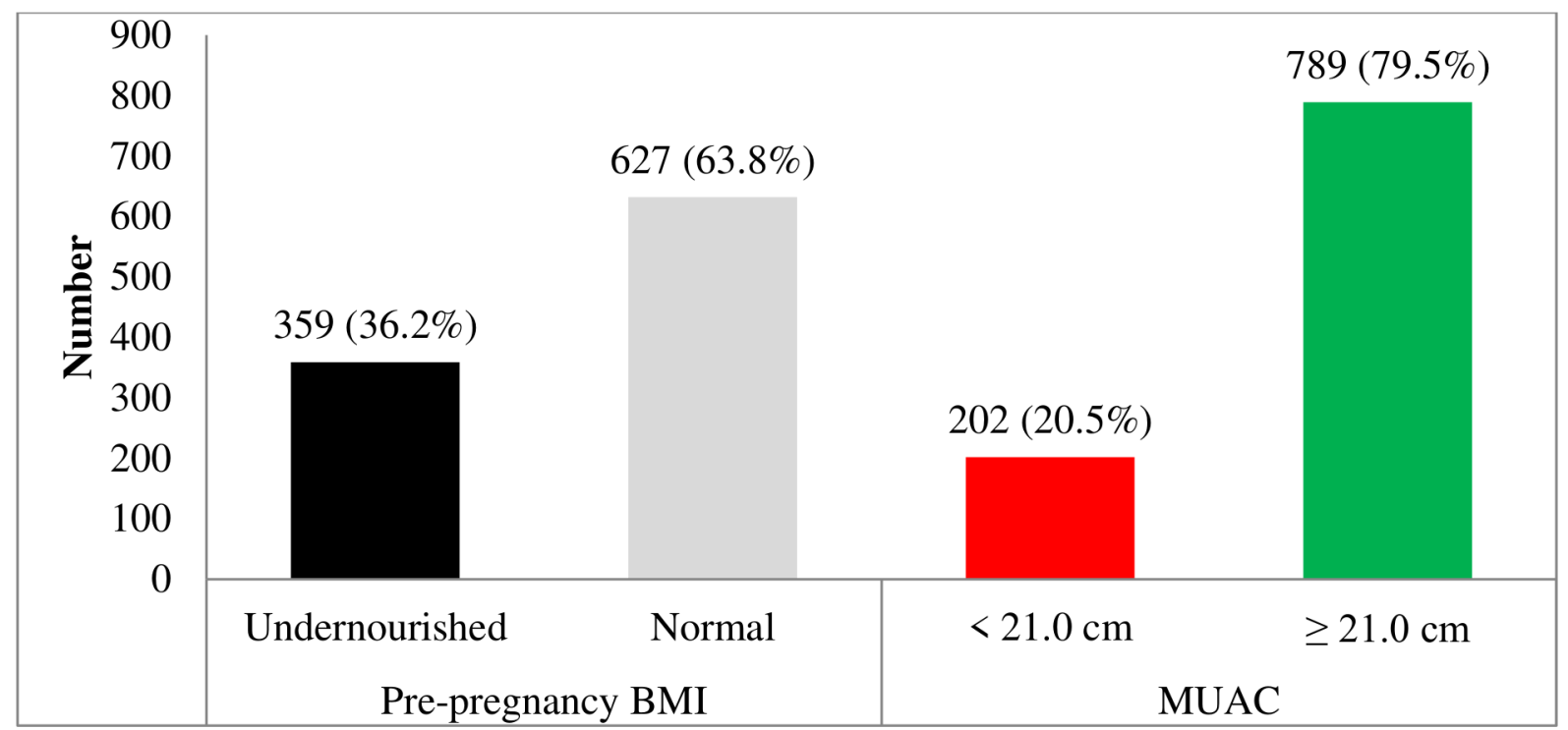

Figure 1 Pre-pregnancy nutritional status as assessed by BMI and MUAC of women, northern Ethiopia, 2018. BMI, body mass index; MUAC, mid-upper arm circumference.

\section{RESULTS}

A total of 991 eligible women were identified and included in the study. Table 1 summarises the anthropometric measures of the participating women by pre-pregnancy BMI categories. The mean pre-pregnancy nutritional status of the women assessed by BMI and MUAC was $19.7 \mathrm{~kg} / \mathrm{m}^{2}$ (SD: $2.0 \mathrm{~kg} / \mathrm{m}^{2}$ ) and $22.6 \mathrm{~cm}$ (SD: $\left.1.9 \mathrm{~cm}\right)$, respectively. Overall, 36.2\% (95\% CI: 33.3 to 39.3 ) were undernourished (BMI: $<18.5 \mathrm{~kg} / \mathrm{m}^{2}$ ) before pregnancy. According to MUAC, the prevalence of undernutrition (MUAC: $<21 \mathrm{~cm}$ ) was $20.5 \%$ (95\% CI: 18.0 to 23.0 ) (see figure 1).

The socioeconomic characteristics of the participants are presented in table 2. On average, the women were 29.3 years old (SD: 6.5 years old) at inclusion. Most women lived in rural areas $(65.3 \%)$, received primary education or below $(69.4 \%)$, and were farmers $(54.6 \%)$. As for their respective household characteristics, 242 (24.4\%) were model households. Also, the majority (89.6\%) had access to an improved drinking water source, whereas only 135 $(13.6 \%)$ had access to an improved sanitation facility. In the unadjusted analysis, better socioeconomic circumstances were associated with higher BMI and MUAC.

Table 3 depicts the reproductive and obstetric conditions, food and dietary as well as psychosocial characteristics. At inclusion, the mean gestational age was 14.8 weeks (SD: 1.9 weeks). The median parity of the women was 2, and $208(21.0 \%)$ had a history of an adverse birth outcome. As for women empowerment, only 114 (11.5\%) were empowered. Additionally, the prevalence of intimate partner violence among women was $16.2 \%$. In the unadjusted analysis, higher women empowerment was associated with higher BMI and MUAC, whereas higher intimate partner violence was associated with lower BMI and MUAC.

As shown in table 3, most women's food and dietary characteristics were poor. In total, 518 women $(52.3 \%)$ had adequate dietary diversity. With reference to dietary habits, most women $(70.0 \%)$ fasted. Additionally, 392 women $(39.6 \%)$ did not have adequate food security. In the unadjusted analysis, higher dietary diversity and agrobiodiversity showed significant associations with higher BMI and MUAC. However, fasting and food insecurity were associated with lower BMI and MUAC.

Furthermore, psychosocial problems were widespread among the women, as indicated in table 3. More than one in five $(21.9 \%)$ women had high symptoms of distress in one of the three domains of distress. Concerning social support, 75 women $(7.6 \%)$ reported low social support. In the unadjusted analysis, a higher total distress score was associated with lower BMI and MUAC, whereas higher total social support score was associated with higher BMI and MUAC.

Results of the unadjusted and adjusted linear regression analyses are given in table 4 . In the adjusted model, age $<30$ years (coefficient: 0.08 , 95\% CI: 0.03 to 0.14 ), being from a model household (coefficient: $0.40,95 \%$ CI: 0.15 to 0.66 ) and women empowerment score $\geq 6$ (coefficient: $0.35,95 \%$ CI: 0.18 to 0.53 ) were positively associated with BMI. From the food and dietary domain, higher dietary diversity (coefficient: $0.13,95 \%$ CI: 0.05 to 0.22 ) was associated with higher BMI. Additionally, fasting (coefficient: $-0.26,95 \%$ CI: -0.50 to -0.02 ), food insecurity (coefficient: $-0.07,95 \% \mathrm{CI}:-0.10$ to -0.05$)$ and agrobiodiversity score $<2$ (coefficient: $-0.62,95 \%$ CI: -1.07 to -0.16 ) were negatively associated with BMI. In total, the model explained $39.5 \%$ of the variation.

All variables that were associated with pre-pregnancy BMI were also associated with MUAC. Of these variables that had a larger effect, being from a model household (coefficient: $0.38,95 \%$ CI: 0.13 to 0.63 ) and women empowerment score $\geq 6$ (coefficient: $0.30,95 \%$ CI: 0.13 to 0.48 ) were positively associated with MUAC. However, fasting (coefficient: $-0.27,95 \%$ CI: -0.51 to -0.03 ) 
Table 2 Socioeconomic characteristics of women and their households ( $n=991)$, Tigray region, northern Ethiopia, 2018

\begin{tabular}{|c|c|}
\hline Characteristics & $\begin{array}{l}\mathrm{n}(\%) / \text { mean } \\
\text { (SD)/median } \\
\text { (IQR) }\end{array}$ \\
\hline Age at inclusion in years & $29.3(6.5)$ \\
\hline Residence, rural & $647(65.3 \%)$ \\
\hline \multicolumn{2}{|l|}{ Religion } \\
\hline Orthodox Christian & $977(98.6 \%)$ \\
\hline Others (Muslim and Catholic) & $14(1.4 \%)$ \\
\hline \multicolumn{2}{|l|}{ Educational status } \\
\hline No formal education & $362(36.5 \%)$ \\
\hline Primary education & $326(32.9 \%)$ \\
\hline Secondary education and above & $303(30.6 \%)$ \\
\hline \multicolumn{2}{|l|}{ Occupation } \\
\hline Farmer & $541(54.6 \%)$ \\
\hline Housewife & $337(34.0 \%)$ \\
\hline Employed & $91(9.2 \%)$ \\
\hline Others $^{\star}$ & $22(2.2 \%)$ \\
\hline \multicolumn{2}{|l|}{ Husband educational status } \\
\hline No formal education & $320(32.3 \%)$ \\
\hline Primary education & $366(36.9 \%)$ \\
\hline Secondary education and above & $305(30.8 \%)$ \\
\hline \multicolumn{2}{|l|}{ Husband occupation } \\
\hline Farmer & $515(52.0 \%)$ \\
\hline Employed & $222(22.4 \%)$ \\
\hline Daily labourer & $161(16.2 \%)$ \\
\hline Others $\dagger$ & $93(9.4 \%)$ \\
\hline Family size & $4.5(2.0)$ \\
\hline \multicolumn{2}{|l|}{ Perceived work burden } \\
\hline Easy & $404(40.8 \%)$ \\
\hline Moderate & $442(44.6 \%)$ \\
\hline Difficult & $145(14.6 \%)$ \\
\hline \multicolumn{2}{|l|}{ Physical activity } \\
\hline Low & $527(53.2 \%)$ \\
\hline Moderate & $425(42.9 \%)$ \\
\hline High & $39(3.9 \%)$ \\
\hline \multicolumn{2}{|l|}{ Wealth index } \\
\hline Lowest & $198(20.0 \%)$ \\
\hline Low & $198(20.0 \%)$ \\
\hline Middle & $200(20.2 \%)$ \\
\hline High & $200(20.2 \%)$ \\
\hline Highest & 195 (19.6\%) \\
\hline Model household & $242(24.4 \%)$ \\
\hline Access to health service within 1 hour & $693(69.8 \%)$ \\
\hline History of pre-pregnancy illness & $142(14.3 \%)$ \\
\hline Access to improved drinking water source & $888(89.6 \%)$ \\
\hline
\end{tabular}

Continued

\section{Table 2 Continued}

n (\%)/mean (SD)/median (IQR)

\section{Characteristics}

$788(79.5 \%)$

Time needed to fetch water not exceeding $30 \mathrm{~min}$

Access to improved sanitation facility

$135(13.6 \%)$

*Student, unemployed or others.

†Drivers, students, unemployed or others.

and agrobiodiversity score $<2$ (coefficient: $-0.61,95 \%$ CI: -1.07 to -0.15 ) were negatively associated with MUAC. The model explained $38.5 \%$ of the variation in MUAC.

Results of Poisson regression analysis are given in table 5 . Not being from a model household (incidence rate ratio (IRR): $1.61,95 \%$ CI: 1.26 to 2.06 ), not being empowered woman (IRR: $2.68,95 \%$ CI: 1.58 to 4.52 ), food insecurity (IRR: $1.65,95 \%$ CI: 1.38 to 1.97 ) and inadequate dietary diversity (IRR: $1.66,95 \%$ CI: 1.38 to 2.00 ) were associated with higher incidence rate ratio of pre-pregnancy undernutrition defined as BMI of $<18.5 \mathrm{~kg} / \mathrm{m}^{2}$. All these variables were also associated with pre-pregnancy undernutrition, defined as MUAC of $<21.0 \mathrm{~cm}$.

\section{DISCUSSION}

We performed a population-based study to determine factors associated with pre-pregnancy nutritional status in 991 pregnant women in northern Ethiopia. A considerable part of the women included in the study did not have optimal nutritional status. Overall, nearly one-third were undernourished before pregnancy. These numbers are higher than the national prevalence $(22 \%)$ but comparable to data reported as the regional prevalence in Tigray $(32 \%)^{14}$ and for Africa as a whole $(32 \%) .{ }^{16} \mathrm{In}$ the present study, we were able to identify a wide range of factors that contribute to the persistence of highly prevalent pre-pregnancy undernutrition. Our findings signal that the identified opportunity to curb the transgenerational cycle of malnutrition before pregnancy is not effectively used in developing countries like Ethiopia. Our results may also offer directions and possibilities for targeted interventions to improve the situation.

Age until 29 years was positively associated with prepregnancy nutritional status and negatively but insignificantly after 29 years. This finding implies an association between lower age and lower pre-pregnancy nutritional status. Lower schooling, socioeconomic status and dietary practice could partly explain the relation between lower age and lower nutritional status. Similar finding has been reported by studies in Ethiopia. ${ }^{50} 51$

Being from a model household, a proxy for implementing the so-called health extension package, was positively associated with pre-pregnancy nutritional status. A model household received short-term training on the health extension package, comprising several 
Table 3 Reproductive and obstetric conditions, food and dietary as well as psychosocial characteristics of women $(n=991)$, Tigray region, northern Ethiopia, 2018

\begin{tabular}{|c|c|}
\hline Reproductive and obstetric conditions & $\begin{array}{l}\text { n (\%)/mean } \\
\text { (SD)/median } \\
\text { (IQR) }\end{array}$ \\
\hline Gestational age at inclusion in weeks & $14.8(1.9)$ \\
\hline$\leq 16$ weeks of gestation at inclusion & $874(88.2 \%)$ \\
\hline Age at first marriage & $18(17-20)$ \\
\hline Gravidity before the index pregnancy & $2(1-4)$ \\
\hline Parity before the index pregnancy & $2(1-4)$ \\
\hline Age at first birth $(n=795)$ & $19.9(2.8)$ \\
\hline $\begin{array}{l}\text { Previous inter-birth spacing in months } \\
(\mathrm{n}=607)\end{array}$ & $38(30-48)$ \\
\hline $\begin{array}{l}\text { History of at least one adverse birth } \\
\text { outcome }\end{array}$ & $208(21.0 \%)$ \\
\hline Women empowerment score & $5.6(1.5)$ \\
\hline Empowered women & $114(11.5 \%)$ \\
\hline Intimate partner violence score & $6.9(3.0)$ \\
\hline Experienced intimate partner violence & $161(16.2 \%)$ \\
\hline \multicolumn{2}{|l|}{ Food and dietary characteristics } \\
\hline Meal frequency (times per day) & $3.3(0.6)$ \\
\hline $\begin{array}{l}\text { Meal frequency at least three times per } \\
\text { day }\end{array}$ & $661(72.1 \%)$ \\
\hline Fruits intake (times per month) & $2(1-4)$ \\
\hline Fruits intake at least three times per week & $57(5.7 \%)$ \\
\hline Vegetables intake (times per month) & $4(4-8)$ \\
\hline $\begin{array}{l}\text { Vegetables intake at least three times per } \\
\text { week }\end{array}$ & $93(9.4 \%)$ \\
\hline $\begin{array}{l}\text { Animal-source food intake (times per } \\
\text { month) }\end{array}$ & $4(1-8)$ \\
\hline $\begin{array}{l}\text { Animal-source food intake at least three } \\
\text { times per week }\end{array}$ & $240(24.3 \%)$ \\
\hline $\begin{array}{l}\text { Alcohol intake at least one unit (times per } \\
\text { month) }\end{array}$ & $1(0-3)$ \\
\hline Alcohol intake at least one time per week & $233(23.5 \%)$ \\
\hline Coffee intake (times per day) & $1.4(1.0)$ \\
\hline Coffee intake at least one time per day & $782(78.9 \%)$ \\
\hline Dietary diversity score & $4.6(1.4)$ \\
\hline Adequate dietary diversity & $518(52.3 \%)$ \\
\hline Fasting & $694(70.0 \%)$ \\
\hline Agrobiodiversity score & $2(0-4)$ \\
\hline Harvest volume in quintals & $2.5(0-6)$ \\
\hline Food insecurity score & $0(0-8)$ \\
\hline Food insecure & $392(39.6 \%)$ \\
\hline \multicolumn{2}{|l|}{ Psychosocial characteristics } \\
\hline Total social support score & $21.3(3.8)$ \\
\hline Low total social support score & $75(7.6 \%)$ \\
\hline Total distress score & $19.1(9.7)$ \\
\hline Level of distress & \\
\hline
\end{tabular}

Continued
Table 3 Continued

n (\%)/mean (SD)/median (IQR)

\begin{tabular}{ll} 
Reproductive and obstetric conditions & (IQR) \\
\hline Not distressed at all & $550(55.5 \%)$ \\
Distressed in one domain & $217(21.9 \%)$ \\
Distressed in two domains & $130(13.1 \%)$ \\
Distressed in three domains & $94(9.5 \%)$
\end{tabular}

components, including maternal health, family planning, nutrition and sanitation. After the training, implementation of the package was required to be labelled as a model household. In addition, HEWs educate women, individually at their home and in a group at a health post, on maternal health, including nutrition during their pregnancy. Therefore, it is likely that the observed association between implementation of the health extension package and better nutritional status is at least in part explained by the effect of the training on dietary practices and the impact of implementing the package on the overall health of the women. ${ }^{52-55}$ This promising finding suggests that strengthening the health extension programme may be a good approach to improving maternal nutritional status.

Moreover, a higher women empowerment score was associated with higher pre-pregnancy nutritional status in the present study, which is in line with the literature. ${ }^{23} 557$ This may be partly explained by the effect of women empowerment on access to food, dietary practice and seeking healthcare. ${ }^{58-64}$ Therefore, the observed association reflects the importance of considering women empowerment in confronting maternal undernutrition and its consequent effects. In short, finding a means for improving the women's social, economic, political and legal strength, ensuring equal rights for women and making them confident enough to claim these rights, such as purchasing resources they want and using healthcare they need, may be helpful.

In congruence with the literature, we observed a positive association between dietary diversity and prepregnancy nutritional status. ${ }^{196566}$ As dietary diversity is seen as a proxy of dietary quality, higher dietary diversity can translate to better nutritional status. ${ }^{67}$ Likewise, the negative association found between food insecurity score and pre-pregnancy nutritional status, consistent with the literature, ${ }^{196869}$ could be explained by inadequate dietary intake or quality due to lack of access to food. ${ }^{70-73}$ Also, a lower agrobiodiversity score was negatively associated with pre-pregnancy nutritional status. Though previous findings are mixed, as shown in a recent review, ${ }^{74}$ the observed association may suggest that a slight change in agrobiodiversity is not enough to positively impact maternal diet and nutrition. Moreover, it may be related to the opportunity costs of farm specialisation due to the foregone gains from diversification. 


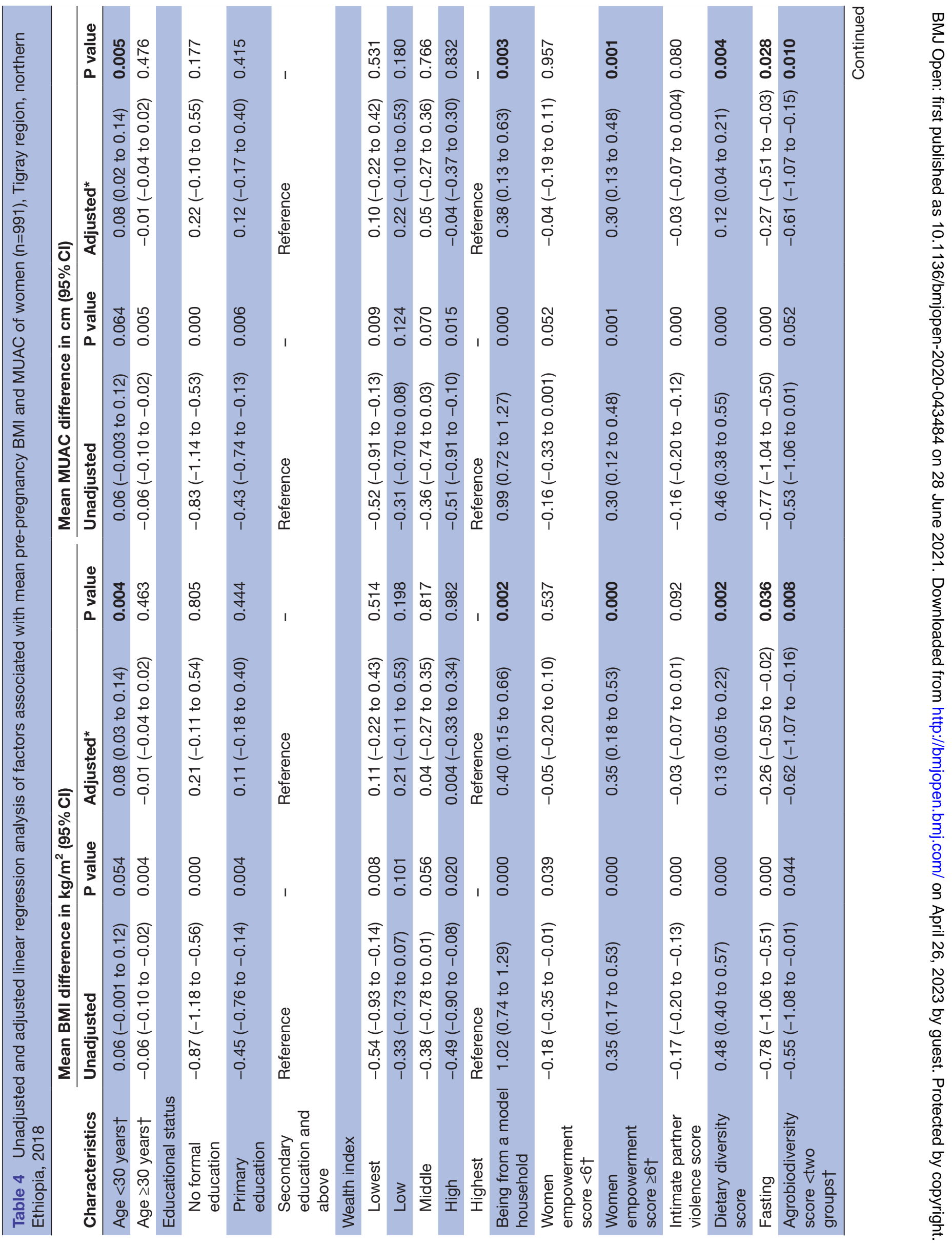




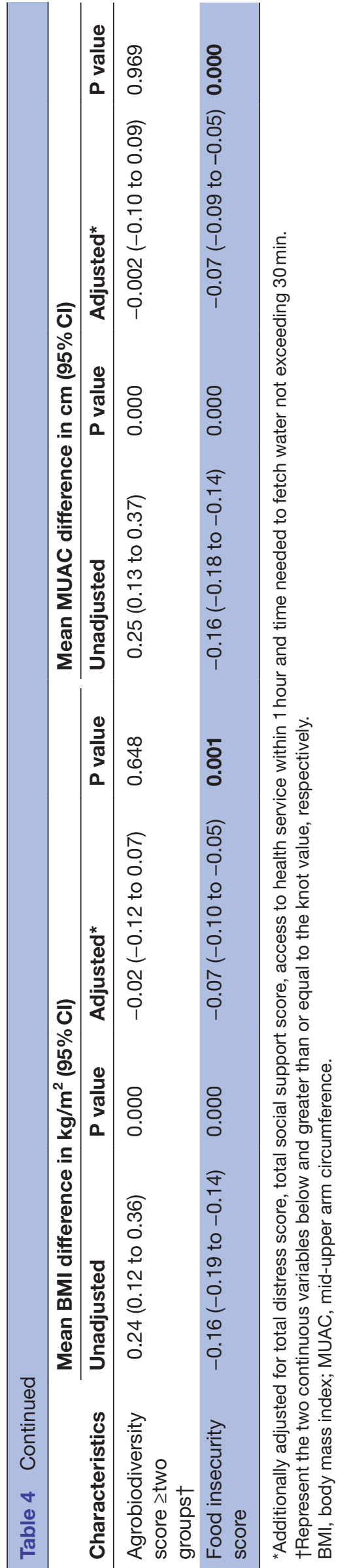

Our study also revealed that fasting was negatively associated with pre-pregnancy nutritional status, which corresponds with a previous study among lactating women. ${ }^{50}$ Almost all the women involved in our study were Orthodox Christians, and in this religion, more than half of the days in a full year are fasting times. This includes regular fasting days almost every Wednesday and Friday throughout the year. The long fasting periods include the 40-day Christmas fast, the 55-day Lenten fast, the 14-day Apostles fast and the 14-day Dormition fast. People are expected to abstain from animal-source foods for religious reasons during these times. This could result in poor dietary quality and poor nutritional status. ${ }^{75} 76$ This finding highlights the importance of considering nutrition-sensitive religious practices as part of the efforts to improve maternal nutrition.

The present study's findings indicate that coordinated and considerable efforts of different bodies and functions might be needed to address pre-pregnancy undernutrition. For instance, involving the agricultural sector in mounting better access to food and involving the justice sector in tackling domestic violence may be helpful. Also, though the Orthodox Church nowadays shows flexibility on fasting during pregnancy, most pregnant women still adhere to fasting for religious reasons. Maintaining this practice will counteract other measures to solve prepregnancy undernutrition. Moreover, physical work like farming activities is not allowed on almost half of the days in a year, that is, all saints days and the weekends, which may worsen food insecurity and dietary quality. Thus, involving religious leaders to improve pre-pregnancy maternal nutrition could be supportive.

\section{Strengths and limitations}

Our study has some strengths and limitations. Using weight measured during a distinct period before starting recruitment of pregnant women, including a relatively large sample of women, and collecting information on many possible confounders can be considered strengths. As for limitations, MUAC was measured at inclusion, unlike BMI. However, as MUAC is relatively insensitive to change over time, it can safely represent the prepregnancy status. ${ }^{17} 18$ Additionally, seasonal variation was not addressed in the dietary diversity measurements. However, agrobiodiversity and food insecurity have been assessed, and adjusting for these variables may account for the bias that can be introduced due to the seasonal variation. Therefore, we do not believe that these limitations have seriously affected the generalisability of our findings. Finally, our study might not have been free of type one error due to the multiple hypothesis testing.

\section{Conclusions}

Pre-pregnancy undernutrition was prevalent in the women living in the study area. The findings of the present study suggest that considerable improvements could be made by advancing community awareness related to dietary practice and habits, also in the area of gender equality. 


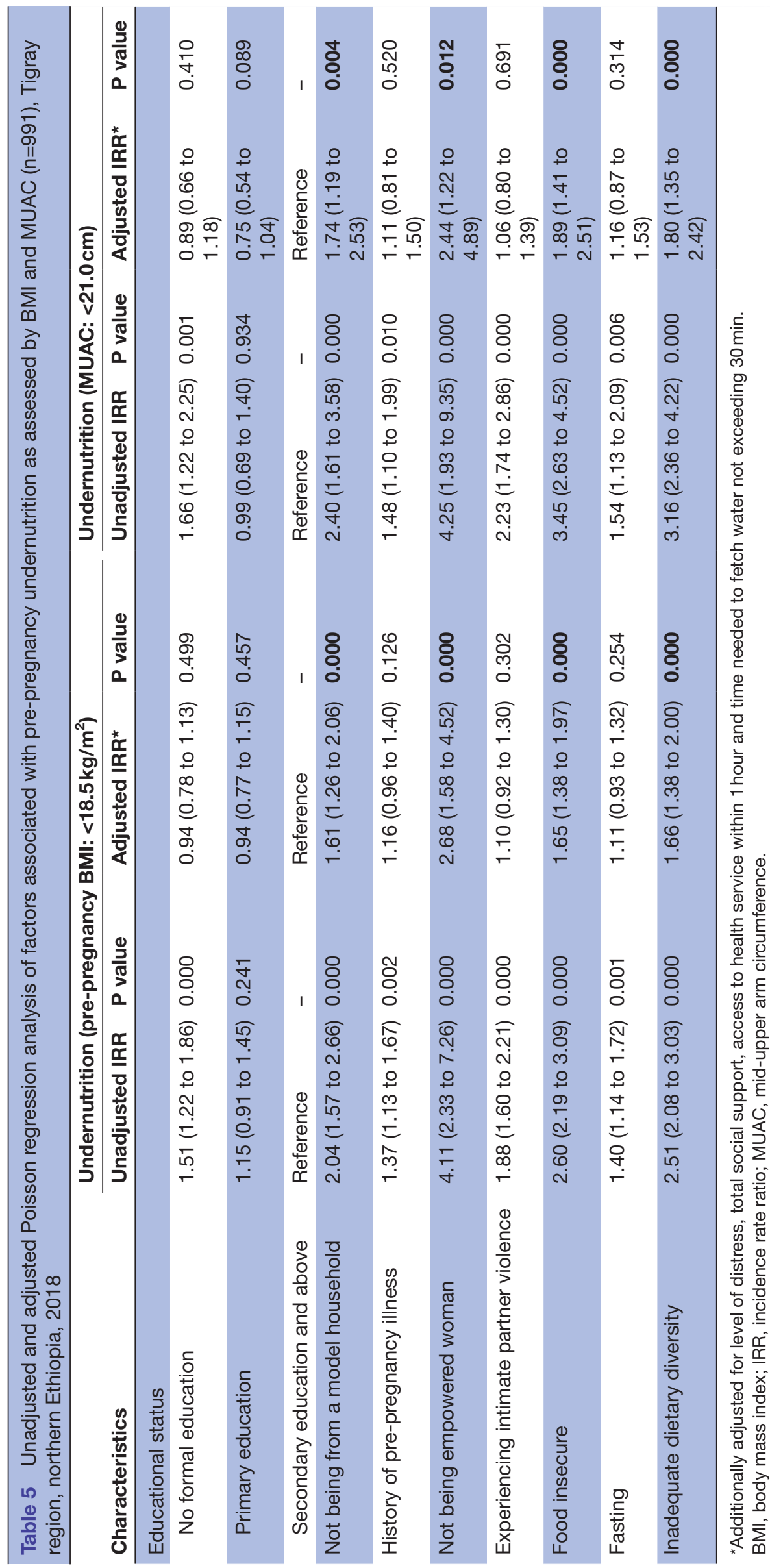


Empowering females, raising agricultural productivity and broader implementation of the health extension package are all factors that may improve maternal nutritional status. In the Ethiopian setting, this would require the coordinated efforts of concerned bodies, including religious leaders.

\section{Twitter Henk Groen @Groen62H}

Acknowledgements The University of Groningen, Aksum University and Mekelle University are acknowledged for their valuable support. Our gratitude goes to the regional health bureau, district health offices, supervisors, data collectors as well as women who participated in this study. We are also thankful to the Central Statistics Agency of Ethiopia and district health bureaus, including Tahtay-Maychew, who allowed us to use their scales for anthropometric measurements. Finally, we appreciate the help of Haileselasie Berhane Alema and Shewit Engdashet Berhe, who entered the data.

Contributors KHM, HG, HMB, EMvdB and AM designed the study. KHM, $\mathrm{HG}$ and $\mathrm{AM}$ were involved in the data collection. $\mathrm{KHM}$ and $\mathrm{HG}$ analysed the data. $\mathrm{KHM}, \mathrm{HG}, \mathrm{HMB}$ and $\mathrm{EMvdB}$ interpreted the data and prepared the manuscript.

Funding The authors have not declared a specific grant for this research from any funding agency in the public, commercial or not-for-profit sectors.

Competing interests None declared.

Patient and public involvement Patients and/or the public were not involved in the design, or conduct, or reporting, or dissemination plans of this research.

Patient consent for publication Not required.

Ethics approval Ethical clearance was acquired from the Institutional Research Review Board of College of Health Science, Aksum University (reference number: IRB 026/2017; dated: 15 August 2017). Permission letter was attained from the regional health bureau and respective district health offices. Also, verbal consent was obtained from each study participant before data collection.

Provenance and peer review Not commissioned; externally peer reviewed.

Data availability statement Data are available upon reasonable request from the corresponding author.

Open access This is an open access article distributed in accordance with the Creative Commons Attribution Non Commercial (CC BY-NC 4.0) license, which permits others to distribute, remix, adapt, build upon this work non-commercially, and license their derivative works on different terms, provided the original work is properly cited, appropriate credit is given, any changes made indicated, and the use is non-commercial. See: http://creativecommons.org/licenses/by-nc/4.0/.

\section{ORCID iDs}

Kebede Haile Misgina http://orcid.org/0000-0002-5492-9152

Henk Groen http://orcid.org/0000-0002-6629-318X

\section{REFERENCES}

1 Black RE, Victora CG, Walker SP, et al. Maternal and child undernutrition and overweight in low-income and middle-income countries. Lancet 2013;382:427-51.

2 Rahman MM, Abe SK, Kanda M, et al. Maternal body mass index and risk of birth and maternal health outcomes in low- and middleincome countries: a systematic review and meta-analysis. Obes Rev 2015;16:758-70.

3 Li N, Liu E, Guo J, et al. Maternal prepregnancy body mass index and gestational weight gain on pregnancy outcomes. PLoS One 2013;8:e82310.

4 Yu Z, Han S, Zhu J, et al. Pre-Pregnancy body mass index in relation to infant birth weight and offspring Overweight/Obesity: a systematic review and meta-analysis. PLoS One 2013;8:e61627.

5 Pan Y, Zhang S, Wang Q, et al. Investigating the association between prepregnancy body mass index and adverse pregnancy outcomes: a large cohort study of 536098 Chinese pregnant women in rural China. BMJ Open 2016;6:e011227-8.

6 Rahman MM, Abe SK, Rahman MS, et al. Maternal anemia and risk of adverse birth and health outcomes in low- and middle-income countries: systematic review and meta-analysis. Am J Clin Nutr 2016;103:495-504

7 Assefa N, Berhane Y, Worku A. Wealth status, mid upper arm circumference (MUAC) and antenatal care (Anc) are determinants for low birth weight in Kersa, Ethiopia. PLoS One 2012;7:e39957.
8 Negash C, Whiting SJ, Henry CJ, et al. Association between maternal and child nutritional status in Hula, rural southern Ethiopia: a cross sectional study. PLoS One 2015;10:e0142301-8.

9 Khan MN, Rahman MM, Shariff AA, et al. Maternal undernutrition and excessive body weight and risk of birth and health outcomes. Arch Public Health 2017;75:1-10.

10 Catalano PM, Farrell K, Thomas A, et al. Perinatal risk factors for childhood obesity and metabolic dysregulation. Am J Clin Nutr 2009;90:1303-13.

11 Victora CG, Adair L, Fall C, et al. Maternal and child undernutrition: consequences for adult health and human capital. Lancet 2008;371:340-57.

12 Fogelman A. Issues in Brief The Changing Shape of Malnutrition: Obesity in sub-Saharan Africa, 2009.

13 Milton AH, Smith W, Rahman B, et al. Prevalence and determinants of malnutrition among reproductive aged women of rural Bangladesh. Asia Pac J Public Health 2010;22:110-7.

14 CSA and ICF International. Ethiopia demographic and health survey 2016. Addis Ababa, Ethiopia and Calverton, Maryland, USA: Central Statistical Agency and ICF International, 2016: 1-452.

15 Bhutta ZA, Das JK, Rizvi A, et al. Evidence-based interventions for improvement of maternal and child nutrition: what can be done and at what cost? Lancet 2013;382:452-77.

16 Desyibelew HD, Dadi AF, Demelash H. Burden and determinants of malnutrition among pregnant women in Africa: a systematic review and meta-analysis. PLoS One 2019;14:e0221712.

17 Maternal anthropometry and pregnancy outcomes. A WHO Collaborative Study. Bull World Health Organ 1995;73Suppl(Suppl):1-98.

18 Krasovec K, Anderson MA, Organization PAH. Maternal Nutrition and Pregnancy Outcomes: Anthropometric Assessment. Pan American Health Organization, 1995.

19 Abraham S, Miruts G, Shumye A. Magnitude of chronic energy deficiency and its associated factors among women of reproductive age in the Kunama population, Tigray, Ethiopia, in 2014. BMC Nutr 2015;1:1-9.

20 Haileslassie K, Mulugeta A, Girma M. Feeding practices, nutritional status and associated factors of lactating women in Samre Woreda, South eastern zone of Tigray, Ethiopia. Nutr J 2013;12:1.

21 Headen IE, Davis EM, Mujahid MS, et al. Racial-Ethnic differences in pregnancy-related weight. Adv Nutr 2012;3:83-94.

22 Tebekaw Y, Teller C, Colón-Ramos U. The burden of underweight and overweight among women in Addis Ababa, Ethiopia. BMC Public Health 2014;14:1126.

23 Alaofè H, Zhu M, Burney J, et al. Association between women's Empowerment and maternal and child nutrition in Kalalé district of northern Benin. Food Nutr Bull 2017;38:302-18.

24 Pratley P. Associations between quantitative measures of women's empowerment and access to care and health status for mothers and their children: a systematic review of evidence from the developing world. Soc Sci Med 2016;169:119-31.

25 Assefa Y, Gelaw YA, Hill PS, et al. Community health extension program of Ethiopia, 2003-2018: successes and challenges toward universal coverage for primary healthcare services. Global Health 2019;15:1-11.

26 Medhanyie A, Spigt M, Kifle Y, et al. The role of health extension workers in improving utilization of maternal health services in rural areas in Ethiopia: a cross sectional study. BMC Health Serv Res 2012;12:1.

27 Yitayal M, Berhane Y, Worku A, et al. Health extension program factors, frequency of household visits and being model households, improved utilization of basic health services in Ethiopia. BMC Health Serv Res 2014;14:156.

28 Kabeer N. Resources, Agency, Achievements: Reflections on the Measurement of Women's Empowerment. Dev Change 1999;30:435-64.

29 WHO Expert Committee. Physical status: the use and interpretation of anthropometry. WHO technical report series 854. Geneva: WHO, 1998.

30 Asefa F, Nemomsa D. Gestational weight gain and its associated factors in Harari regional state: institution based cross-sectional study, eastern Ethiopia. Reprod Health 2016;13:1-7.

31 Zerfu TA, Umeta M, Baye K. Dietary diversity during pregnancy is associated with reduced risk of maternal anemia, preterm delivery, and low birth weight in a prospective cohort study in rural Ethiopia. Am J Clin Nutr 2016;103:1482-8.

32 Coates J, Swindale A. Household food insecurity access scale (HFIAS) for measurement of food access: indicator guide version. $J$ Chem Inf Model 2013;53:1689-99.

$33 \mathrm{FAO} \& \mathrm{FHI} 360$. Minimum dietary diversity for Women- a guide to measurement, 2016. 
34 The International Physical Activity Questionnaire. Short last 7 days self-administered format, 2002. Available: http://www.ipaq.ki.se

35 World Food Program. Creation of a wealth index, 2017: 1-26.

$36 \mathrm{WHO}$ /UNICEF. Progress on sanitation and DrWorld health organization UNICEF joint monitoring programme for water supply and Sanitationinking water: update 2010. WHO Library, 2010: 1-55.

37 International Physical Activity Questionnaire. IPAQ scoring protocol. 15, 2005.

38 Rabin RF, Jennings JM, Campbell JC, et al. Intimate partner violence screening tools. Am J Prev Med 2009;36:439-45.

39 Jennings $\mathrm{L}, \mathrm{Na} M$, Cherewick M, et al. Women's empowerment and male involvement in antenatal care: analyses of Demographic and Health Surveys (DHS) in selected African countries. BMC Pregnancy Childbirth 2014;14:1-11.

40 Malapit HJL, Quisumbing AR. What dimensions of women's empowerment in agriculture matter for nutrition in Ghana? Food Policy 2015;52:54-63.

41 Gitagia MW, Ramkat RC, Mituki DM, et al. Determinants of dietary diversity among women of reproductive age in two different agroecological zones of Rongai Sub-County, Nakuru, Kenya. Food Nutr Res 2019;63:1-12.

42 Cheng ER, Rifas-Shiman SL, Perkins ME, et al. The influence of antenatal partner support on pregnancy outcomes. J Womens Health 2016;25:672-9.

43 Kocalevent R-D, Berg L, Beutel ME, et al. Social support in the general population: standardization of the Oslo social support scale (OSSS-3). BMC Psychol 2018;6:4-11.

44 Cox JL, Holden JM, Sagovsky R. Detection of postnatal depression. Br J Psychiatry 1987;150:782-6.

45 Zigmond AS, Snaith RP. The hospital anxiety and depression scale. Acta Psychiatr Scand 1983;67:361-70.

46 Karam F, Bérard A, Sheehy O, et al. Reliability and validity of the 4item perceived stress scale among pregnant women: results from the OTIS antidepressants study. Res Nurs Health 2012;35:363-75.

47 The Sphere. The sphere Handbook: humanitarian charter and minimum standards in humanitarian response, 2018.

48 UCLA Statistical Consulting Group. Stata FAQ how can I run a piecewise regression in Stata? 2011: 1-7.

49 Barros AJD, Hirakata VN. Alternatives for logistic regression in crosssectional studies: an empirical comparison of models that directly estimate the prevalence ratio. BMC Med Res Methodol 2003;3:21.

50 Desalegn BB, Lambert C, Riedel S, et al. Ethiopian orthodox fasting and lactating mothers: longitudinal study on dietary pattern and nutritional status in rural tigray, Ethiopia. Int J Environ Res Public Health 2018;15:1767-20.

51 Workicho A, Belachew T, Argaw A, et al. Maternal nutritional status mediates the association between maternal age and birth outcomes. Matern Child Nutr 2020;16:e13015.

52 Yitayal M, Berhane Y, Worku A, et al. The community-based health extension program significantly improved contraceptive utilization in West Gojjam zone, Ethiopia. J Multidiscip Healthc 2014;7:201-8.

53 Medhanyie A, Spigt M, Kifle Y, et al. The role of health extension workers in improving utilization of maternal health services in rural areas in Ethiopia: a cross sectional study. BMC Health Serv Res 2012;12:352.

54 Tafesse N, Gesessew A, Kidane E. Urban health extension program model housing and household visits improved the utilization of health services in urban Ethiopia: a community-based cross-sectional study. BMC Health Serv Res 2019;19:1-11.

55 Negussie A, Girma G. Is the role of health extension workers in the delivery of maternal and child health care services a significant attribute? the case of dale district, southern Ethiopia. BMC Health Serv Res 2017:17:1-8.

56 Tebekaw Y. The demographic transition and development in Africa. Demogr Transit Dev Africa 2011:105-24.

57 Malapit HJL, Kadiyala S, Quisumbing AR, et al. Women's Empowerment Mitigates the Negative Effects of Low Production
Diversity on Maternal and Child Nutrition in Nepal. J Dev Stud 2015;51:1097-123.

58 Amugsi DA, Lartey A, Kimani E, et al. Women's participation in household decision-making and higher dietary diversity: findings from nationally representative data from Ghana. $J$ Health Popul Nutr 2016;35:16

59 Ghose B, Feng D, Tang S, et al. Women's decision-making autonomy and utilisation of maternal healthcare services: results from the Bangladesh Demographic and Health Survey. BMJ Open 2017;7:e017142-8

60 Ousman SK, Mdala I, Thorsen VC, et al. Social determinants of antenatal care service use in Ethiopia: changes over a 15-year span. Front Public Health 2019;7:1-10.

61 Ahmed S, Creanga AA, Gillespie DG, et al. Economic status, education and empowerment: implications for maternal health service utilization in developing countries. PLoS One 2010;5:e11190.

62 Pandey S, Lama G, Lee H. Effect of women's empowerment on their utilization of health services: A case of Nepal. Int Soc Work 2012;55:554-73.

63 Sado L, Spaho A, Hotchkiss DR. The influence of women's empowerment on maternal health care utilization: evidence from Albania. Soc Sci Med 2014;114:169-77.

64 Adhikari R. Effect of Women's autonomy on maternal health service utilization in Nepal: a cross sectional study. BMC Womens Health 2016;16:1-7.

65 Ersino G, Zello GA, Henry CJ, et al. Gender and household structure factors associated with maternal and child undernutrition in rural communities in Ethiopia. PLoS One 2018;13:e0203914-20.

66 Amugsi DA, Dimbuene ZT, Bakibinga P, et al. Dietary diversity, socioeconomic status and maternal body mass index (BMI): quantile regression analysis of nationally representative data from Ghana, Namibia and Sao Tome and Principe. BMJ Open 2016;6:e012615.

67 Arimond M, Wiesmann D, Becquey E, et al. Simple food group diversity indicators predict micronutrient adequacy of women's diets in 5 diverse, resource-poor settings. J Nutr 2010;140:2059S-69.

$68 \mathrm{McDonald} \mathrm{CM}$, McLean J, Kroeun H, et al. Household food insecurity and dietary diversity as correlates of maternal and child undernutrition in rural Cambodia. Eur J Clin Nutr 2015;69:242-6.

69 Cesare MD, Bhatti Z, Soofi SB, et al. Geographical and socioeconomic inequalities in women and children's nutritional status in Pakistan in 2011: an analysis of data from a nationally representative survey. Lancet Glob Health 2015;3:e229-39.

70 Nguyen PH, Avula R, Ruel MT, et al. Maternal and child dietary diversity are associated in Bangladesh, Vietnam, and Ethiopia. J Nutr 2013;143:1176-83

71 Adubra L, Savy M, Fortin S, et al. The minimum dietary diversity for women of reproductive age (MDD-W) indicator is related to household food insecurity and farm production diversity: evidence from rural Mali. Curr Dev Nutr 2019;3:1-9.

$72 \mathrm{Na} \mathrm{M}$, Mehra S, Christian P, et al. Maternal dietary diversity decreases with household food insecurity in rural Bangladesh: a longitudinal analysis. J Nutr 2016;146:2109-16.

73 Kang Y, Hurley KM, Ruel-Bergeron J, et al. Household food insecurity is associated with low dietary diversity among pregnant and lactating women in rural Malawi. Public Health Nutr 2019;22:697-705.

74 Sibhatu KT, Qaim M. Review: meta-analysis of the association between production diversity, diets, and nutrition in smallholder farm households. Food Policy 2018;77:1-18.

75 D'Haene E, Desiere S, D'Haese M, et al. Religion, food choices, and demand seasonality: evidence from the Ethiopian milk market. Foods 2019;8:167-21.

76 Bezabih AM, Wereta MH, Kahsay ZH, et al. Demand and supply side barriers that limit the uptake of nutrition services among pregnant women from rural Ethiopia: an exploratory qualitative study. Nutrients 2018:10. doi:10.3390/nu10111687. [Epub ahead of print: 05 Nov 2018]. 